\title{
Effect of dibutyltin on placental and fetal toxicity in rat
}

\author{
Satoshi Furukawa', Naho Tsuji', Yoshiyuki Kobayashi², Yoshikazu Yamagishi', \\ Seigo Hayashi', Masayoshi Abe', Yusuke Kuroda', Masayuki Kimura', Chisato Hayakawa' \\ and Akihiko Sugiyama ${ }^{3}$
}

\author{
'Biological Research Laboratories, Nissan Chemical Industries, Ltd., \\ 1470 Shiraoka, Shiraoka-shi, Saitama 349-0294, Japan \\ ${ }^{2}$ Chemical Research Laboratories, Nissan Chemical Industries, Ltd., \\ 2-10-1 Tsuboi-nishi, Funabashi, Chiba 274-8507, Japan \\ ${ }^{3}$ Courses of Veterinary Laboratory Medicine, School of Veterinary Medicine, Faculty of Agriculture, \\ Tottori University, 4-101, Koyama-cho Minami Tottori 680-8553, Japan
}

(Received August 3, 2017; Accepted September 26, 2017)

\begin{abstract}
In order to elucidate the effect of chorioallantoic and yolk sac placenta on the embryonic/fetal toxicity in dibutyltin dichloride (DBTCl)-exposed rats, we examined the histopathological changes and the tissue distribution of dibutyltin in the placentas and embryos. DBTCl was orally administered to the groups at doses of $0 \mathrm{mg} / \mathrm{kg}$ during gestation days (GD)s 7-9 (control group) and $20 \mathrm{mg} / \mathrm{kg}$ during GDs 7-9 (GD7-9 treated group), and GDs 10-12 (GD10-12 treated group). The total fetal mortality was increased, and malformations characterized by craniofacial dysmorphism were detected in the GD7-9 treated group. The embryonic/fetal weight and placental weight showed a decrease in both DBTCl-treated groups. Histologically, some embryos on GD 9.5 in the GD7-9 treated group underwent apoptosis without any changes of yolk sac. In the laser ablation-inductively coupled plasma-mass spectrometry analysis (LA-ICP-MS), tin was detected in the embryo, allantois, yolk sac, ectoplacental cone and decidual mass surrounding the conceptus on GD 9.5 in the GD7-9 treated group. Thus, it is considered that the embryo in this period is specifically sensitive to DBTCl-induced apoptosis, compared with other parts. The chorioallantoic placentas in both DBTCl-treated groups showed the developmental delay and hypoplasia in the fetal parts of placenta, resulting from apoptosis and mitotic inhibition. Thus, it was speculated that the DBTCl-induced malformations and fetal resorption resulted from the apoptosis in the embryo caused by the direct effect of DBTCl. The DBTCl-induced lesions in the chorioallantoic placenta were a non-specific transient developmental retardation in the fetal parts of placenta, leading to intrauterine growth retardation.
\end{abstract}

Key words: Dibutyltin, LA-ICP-MS, Malformation, Placenta, Rat

\section{INTRODUCTION}

The amounts of organotin released into the environment have increased with its widespread use in agricultural biocides, wood preservatives, antifouling paints for boats and industrial catalysts, and are a worldwide environmental pollutant. The most important non-pesticidal route of entry of organotin compounds into the environment is through leaching of organotin-stabilized polyvinyl chloride by water. Dibutyltin (DBT) compounds are used primarily as stabilizers for the production of polyvinyl chloride plastic products (Boyer, 1989) and has been found in some plastic food containers (Yamada et al., 1993), since the presence of DBT prevents the degradation of plastics by combining with the hydrochloric acid $(\mathrm{HCl})$ liberated from the polymer during the manufacturing process. The reaction between $\mathrm{HCl}$ and the stabilizer most probably produces dibutyltin dichloride (DBTCl).

DBTCl induces the implantation failure in rats, resulting from the decline in progesterone level (Ema et al., 2003). The oral administration of DBTCl during the organogenetic period in rat results in malformations, such as cleft jaw, ankyloglossia, defects of the mandible, fusion of the ribs and deformity of the vertebral column (Ema

Correspondence: Satoshi Furukawa (E-mail: furukawa@nissanchem.co.jp) 


\section{S. Furukawa et al.}

et al., 1991). There is a susceptible period for these teratogeneses caused by DBTCl in rats. Following maternal exposure to $\mathrm{DBTCl}$ in rats, developing offsprings are susceptible to teratogenic effect during GDs 7-9, but not during GDs 10-12 (Ema et al., 1992). On the other hand, the DBTCl-exposed placenta shows a decreased weight in the organogenetic period treated teratology study. The placenta plays important roles in the maintenance of pregnancy, and the influence on fetal growth and development. The dam and fetus have a close relationship with each other via the placenta and form the maternal-fetal-placental unit in mammalian embryonic development. However, there are no detailed reports describing the histological placental changes after exposure to DBTCl or the effect of placentas on the embryonic and fetal toxicity. In addition, the placental apoptosis can be detected in the normal placental development (Smith et al., 1997), and is an important player in the regulation of feto-placental growth in rats (Waddell et al., 2000). The balance between cell proliferation and apoptosis in the placenta is crucial for successful embryo implantation and maintenance of pregnancy during gestation (Correia-da-Silva et al., 2004). In order to elucidate the effect of chorioallantoic and yolk sac placenta on the embryonic and fetal toxicity in DBTCl-exposed rats, we examined the histopathological changes of placenta and embryo with analysis of apoptosis and cell proliferation as a toxicity index, and the tissue distribution of DBTCl in them after oral administration of DBT$\mathrm{Cl}$ during GDs 7-9 or GDs 10-12.

\section{MATERIALS AND METHODS}

\section{Animals}

Non-pregnant specific pathogen-free Wistar Hannover rats (Japan Laboratory Animals, Inc., Saitama, Japan) were purchased at approximately 10-14 weeks of age. A female rat was housed together with a male rat of the same strain and source for mating. The occurrence of copulation was established by daily inspection for a vaginal plug. Mated female rats were assigned to this study. GD 0 was designated as the day when the presence of vaginal plug was identified. The animals were single-housed in plastic cages on softwood chip bedding in an air-conditioned room $\left(22 \pm 2{ }^{\circ} \mathrm{C}\right.$; humidity, $55 \pm 10 \%$; light cycle, 12 hr/day). Feed (CRF-1: Oriental Yeast Co., Ltd., Tokyo, Japan) and water were available ad libitum.

DBTCl (Tokyo Chemical Industries, Ltd., Tokyo, Japan) was dissolved in olive oil. DBTCl was orally administered to the groups at doses of $0 \mathrm{mg} / \mathrm{kg}$ with olive oil during GDs 7-9 (control) and $20 \mathrm{mg} / \mathrm{kg}$ during GDs 7-9 (the GD7-9 treated group), and GDs 10-12 (the GD10-12 treated group) with a volume of $0.5 \mathrm{~mL} / 100 \mathrm{~g}$ body weight. The treatment of pregnant rats with $\mathrm{DBTCl}$ at $20 \mathrm{mg} / \mathrm{kg}$ was previously reported to have teratogenic effect on fetuses (Ema et al., 1992). All treatments were made between 9 and 11 a.m. The dams were euthanized by exsanguination under anesthesia, and necropsied. These experiments were conducted according to the Guidelines for Animal Experimentation, Japanese Association for Laboratory Animal Science.

\section{Experimental design}

The 85 pregnant rats were randomly allocated to 3 groups of 23-36 rats each. Maternal body weight was recorded on GDs 6-21. The dams were sampled on GDs $9.5,11,13,14,15,17$, and 21 , and then the histopathological examination, inductively coupled plasma-mass spectrometry (ICP-MS) analysis, and laser ablation-inductively coupled plasma-mass spectrometry (LA-ICP-MS) analysis were performed, according to Fig. 1. On GDs 9.5 and 11, the conceptuses with decidual mass were randomly obtained from the dams in the control and GD7-9 treated groups. On GDs 13, 14, 15, 17, and 21, the placentas and yolk sacs were obtained from live embryos/fetuses in each dam in all groups regardless of fetal sex. The placentas were separated between the basal zone and decidua basalis, and were removed from the uterus wall. The embryos/fetuses and placentas for the histopathological examination were weighed, and the fetal-placental weight ratio was calculated individually. In addition, on GDs 17 and 21 , the fetuses were examined for external malformations with the aid of a dissecting microscope. According to the criteria for intrauterine growth retardation (IUGR) evaluation, the fetuses were defined as IUGR if their weight was $<1.15 \mathrm{~g}$ on GD 17 and $<4.64 \mathrm{~g}$ on GD 21, corresponding to -2 standard deviation (SD) of the mean of the control fetuses on each gestation day in the present study (Engelbregt et al., 2001) and the IUGR rate (i.e. the actual number of fetuses exhibiting IUGR as a percentage of the total number of fetuses) was calculated (Huang et al., 2012). All obtained samples were fixed in 10\% neutral buffered formalin.

\section{Histopathological examination}

The formalin-fixed tissues were embedded in paraffin, sectioned at $4 \mu \mathrm{m}$ thickness, and stained routinely with hematoxylin and eosin (HE) for histopathological examination. Immunohistochemical staining, in situ TdT-mediated dUTP nick end labeling (TUNEL) (In Situ Cell Death Detection Kit, POD) (Roche Applied Science, Penzberg, Germany) and phospho-histone H3 (Ser10) (Cell Signaling Technology, Boston, MA, USA) were performed on the 


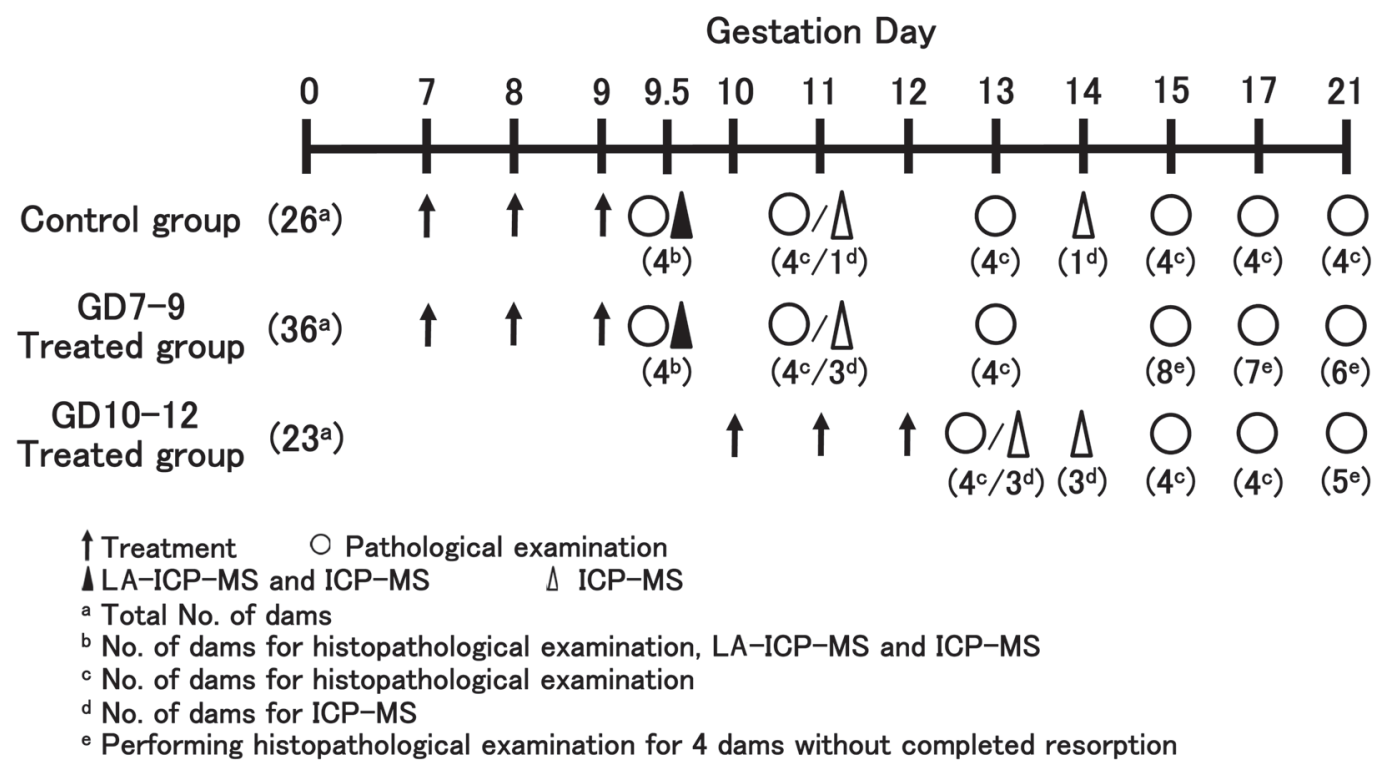

Fig. 1. Experimental design.

conceptuses, placentas and yolk sacs (Furukawa et al., 2017). The histopathological examination was performed with the aid of an image analyzer (WinROOF, Mitani Co., Tokyo, Japan). On GD 9.5, the thickness of uterus, decidua basalis, decidua capsularis, metrial gland and ectoplacental cone and the length of embryo (extraembryonic cavity and amniotic cavity) and the width of embryo were measured in 3 conceptuses with decidual mass from each dam (Fig. 2). In addition, the number of phospho-histone H3 positive cells and TUNEL positive cells in the decidua basalis, embryo, trophectoderm layer and yolk sac were counted in 5 areas by light microscopy with a 40x objective. On GDs $11,13,15,17$, and 21 , the thickness of labyrinth zone, basal zone, decidua basalis and metrial gland close to the central portion were measured in four placentas from each dam. The number of phospho-histone $\mathrm{H} 3$ positive cells and TUNEL positive cells in the labyrinth zone, basal zone, metrial gland and visceral yolk sac were counted in 20 areas by light microscopy with a 40x objective.

\section{Tissue concentration of tin by ICP-MS}

The formalin-fixed tissues of conceptuses with decidual mass on GD 9.5, and the embryos, placentas, yolk sacs on GDs 11, 13 and/or 14 were analyzed by ICPMS. The number of each analyzed tissue was one litter in the control group and three litters in both DBTCl-treated groups at each sampling point according to Fig. 1. For the preparation of sample solutions, $50-300 \mathrm{mg}$ of sample was weighed into a polytetrafluoroethylene digestion vessel and digested with $3 \mathrm{~mL}$ of nitric acid and $1 \mathrm{~mL}$ of hydrochloric acid by microwave heating (UltraWAVE, Milestone General, Kanagawa, Japan). After cooling the vessel to room temperature and venting it carefully, the sample solutions were diluted to $15 \mathrm{~mL}$ with ultrapure water and injected to an inductively coupled plasma mass spectrometer, Agilent 7500cs (Agilent Technologies, Santa Clara, CA, USA). Working standard solutions were daily prepared from the tin standard stock solution for atomic absorption spectrochemical analysis $(1,000 \mathrm{mg} / \mathrm{L}$, Wako Pure Chemical Industries, Osaka, Japan). The peak area of ${ }^{118} \mathrm{Sn}$ intensity was used for quantification.

\section{Histological localization of tin in conceptus on GD 9.5 by LA-ICP-MS}

Since it is impossible to analyze tin distribution in the embryo and yolk sac in the conceptus on GD 9.5 by ICP-MS, the histological localization of tin was detected with LA-ICP-MS. The number of each analyzed tissue was one conceptus from each of two dams in the control group and one conceptus from each of four dams in the GD7-9 treated group for the LA-ICP-MS analysis (Fig. 1). The paraffin sections of the conceptus on GD 9.5 in the control and GD7-9 treated groups were analyzed by an LSX-213 G2+ system (Teledyne CETAC Technologies, Omaha, NE, USA) with iCAP RQ (Thermo Fisher Scientific, Waltham, MA, USA) imaging method. The condition of LA-ICP-MS was as previously reported with minor modifications (Yamagishi et al., 2016). Modified 

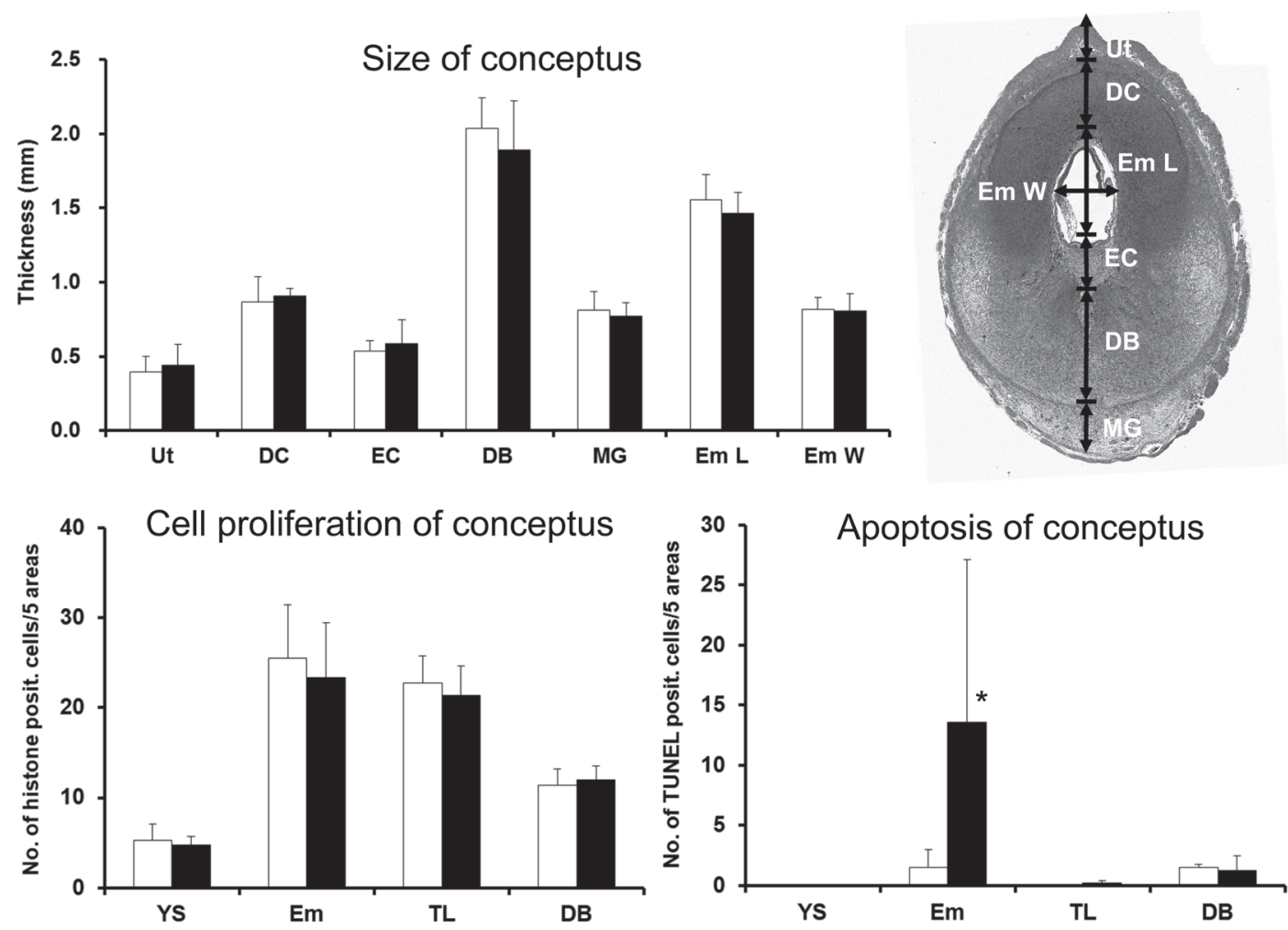

Fig. 2. Measurement of conceptus on GD 9.5. Ut, Uterus; DC, Decidua capsularis; EC, Ectoplacental Cone; DB, Decidua basalis; MG, Metrial gland; Em, Embryo; EmL, length of embryo (extraembryonic cavity and amniotic cavity); EmW, width of embryo (extraembryonic cavity); YS, Yolk sac; TL, Trophectoderm layer. Number of phospho-histone H3 positive cells and TUNEL positive cells in 5 areas by light microscopy with a 40x objective. $\square$, Control group; $\mathbf{m}$, GD7-9 treated group. Each value represents mean \pm S.D. *Significantly different from control at $P<0.05$, respectively (Student's t-test or Wilcoxon rank sum test).

conditions were as follows: a laser spot size, $20 \mu \mathrm{m}$; scan rate, $125 \mu \mathrm{m} / \mathrm{s}$; a carrier gas, $0.8 \mathrm{~L} / \mathrm{min}$; a quartz injector pipe with an inner diameter of $2.5 \mathrm{~mm}$; dwell time, $15 \mathrm{~ms}$; and isotopes monitored, ${ }^{118} \mathrm{Sn},{ }^{56} \mathrm{Fe}$ and ${ }^{64} \mathrm{Zn}$.

\section{Statistical analysis}

Means and SD of the individual litter values were calculated (Pharmaco Basic, Scientist Press Co. Ltd., Tokyo, Japan). In comparison between two groups, the Student's t-test for homoscedastic data and the Wilcoxon rank sum test for non-homoscedastic data were performed after $\mathrm{F}$ test. In comparison among 3 groups, when variances were homogeneous after the Bartlett's test, the Dunnett's multiple comparison test was performed. The Steel's multiple comparison test was employed, when variances were not homogeneous. In the IUGR rate and the number of accumulated dams with completed resorption, Chi-squared analysis was performed. The level of significance was set at $P<0.05$ and $<0.01$.

\section{RESULTS}

\section{Effect on dams}

Body weight gain (\%) of dams in both DBTCl-treated groups (based on the body weight on GD 6 as 100\%) decreased from one day after treatment and continued declining until the end of experimental period, compared with the control group. There was no death or clinical sign of dams in all groups. The accumulated dams with completed resorption was increased from GD 15 onward, and there was a decrease in the total living fetuses per litter and an increase in the total fetal mortality (58.2\%) in the GD7-9 treated group (Table 1).

\section{Effect on embryo/fetus and placenta}

The effect of DBTCl on embryo/fetus and placenta except the litters with complete fetal resorption are shown in Table 2. The embryonic/fetal mortality was increased from GD 15 onward and reached up to $63.6 \%$ on GD 21 
Effect of DBT on placental and fetal toxicity in rat

Table 1. Effect of DBTCl on completed resorption and total fetal mortality.

\begin{tabular}{|c|c|c|c|c|c|c|c|c|}
\hline \multirow{3}{*}{ Group } & \multirow{3}{*}{$\begin{array}{l}\text { No. of } \\
\text { dams }\end{array}$} & \multicolumn{4}{|c|}{$\begin{array}{l}\text { Accumulated dams with completed } \\
\text { resorption }(\%)\end{array}$} & \multirow{3}{*}{$\begin{array}{c}\text { Total No.of } \\
\text { implantations per } \\
\text { litter }^{\text {b) }}\end{array}$} & \multirow{3}{*}{$\begin{array}{l}\text { Total living fetuses } \\
\text { per litter }{ }^{\text {b) }}\end{array}$} & \multirow{3}{*}{$\begin{array}{l}\text { Total fetal mortality } \\
(\%)^{\mathrm{b})}\end{array}$} \\
\hline & & \multicolumn{4}{|c|}{ Gestation day } & & & \\
\hline & & 13 & 15 & 17 & 21 & & & \\
\hline Control & 16 & 0.0 & 0.0 & 0.0 & 0.0 & $12.3 \pm 2.7$ & $12.0 \pm 2.7$ & $2.3 \pm 5.6$ \\
\hline GD7-9 & 25 & 0.0 & $16.0^{s}$ & $28.0^{\mathrm{s}}$ & $36.0^{\$ \$}$ & $11.8 \pm 1.7$ & $7.4 \pm 5.1 * *$ & $58.2 \pm 40.5^{* *}$ \\
\hline GD10-12 & 17 & 0.0 & 0.0 & 0.0 & 5.9 & $11.1 \pm 2.4$ & $9.9 \pm 3.8$ & $11.7 \pm 26.7$ \\
\hline
\end{tabular}

Mean \pm S.D.

a) Except the dams sampled on GDs 9.5 and 11, and the dams sampled for ICP-MS.

b) Mean of individual litter values.

** Significantly different from control at $\mathrm{P}<0.01$ (Dunnett's/Steel's test).

$\$, \$ \$$ Significantly different from control at $\mathrm{P}<0.05,<0.01$, respectively $\left(\mathrm{x}^{2}\right.$ test).

Table 2. Effect of DBTCl on embryos/fetuses and placentas.

\begin{tabular}{|c|c|c|c|c|c|c|c|c|c|}
\hline Autopsy & Group & $\begin{array}{l}\text { No. of } \\
\text { dams }\end{array}$ & $\begin{array}{l}\text { Mean No. of } \\
\text { live fetuses }\end{array}$ & $\begin{array}{l}\text { Embryo/fetus } \\
\text { mortality }(\%)^{a)}\end{array}$ & $\begin{array}{l}\text { Embryo/fetus } \\
\text { weight }(\mathrm{g})^{\mathrm{a})}\end{array}$ & $\begin{array}{l}\text { Placenta weight } \\
(\mathrm{g})^{\text {a) }}\end{array}$ & $\begin{array}{c}\text { Fetus /Placenta } \\
(\mathrm{g} / \mathrm{g})^{\mathrm{a})}\end{array}$ & $\begin{array}{l}\text { IUGR } \\
\text { rate }(\%)\end{array}$ & $\begin{array}{l}\text { Malformations } \\
(\%)^{a)}\end{array}$ \\
\hline \multirow{2}{*}{ GD 9.5} & Control & 4 & $13.3 \pm 1.3$ & $0.0 \pm 0.0$ & NA & NA & NA & NA & NA \\
\hline & GD7-9 & 4 & $12.5 \pm 1.7$ & $0.0 \pm 0.0$ & NA & NA & NA & NA & NA \\
\hline \multirow{2}{*}{ GD 11} & Control & 4 & $12.0 \pm 3.6$ & $0.0 \pm 0.0$ & NA & NA & NA & NA & NA \\
\hline & GD7-9 & 4 & $11.3 \pm 1.0$ & $2.5 \pm 5.0$ & NA & NA & NA & NA & NA \\
\hline \multirow{3}{*}{ GD 13} & Control & 4 & $13.0 \pm 1.4$ & $3.7 \pm 4.3$ & $0.07 \pm 0.01$ & $0.12 \pm 0.01$ & $0.56 \pm 0.03$ & NA & NA \\
\hline & GD7-9 & 4 & $11.3 \pm 0.5$ & $2.1 \pm 4.2$ & $0.05 \pm 0.01 * *$ & $0.10 \pm 0.01 *$ & $0.52 \pm 0.15$ & NA & NA \\
\hline & GD10-12 & 4 & $11.5 \pm 2.4$ & $0.0 \pm 0.0$ & $0.05 \pm 0.01^{*}$ & $0.10 \pm 0.01$ & $0.44 \pm 0.05$ & NA & NA \\
\hline \multirow{3}{*}{ GD 15} & Control & 4 & $12.5 \pm 3.1$ & $9.8 \pm 10.7$ & $0.26 \pm 0.02$ & $0.22 \pm 0.02$ & $1.12 \pm 0.12$ & NA & NA \\
\hline & GD7-9 & $4^{b}$ & $7.3 \pm 3.3$ & $44.4 \pm 20.5^{*}$ & $0.19 \pm 0.02 *$ & $0.14 \pm 0.01 * *$ & $1.35 \pm 0.24$ & NA & NA \\
\hline & GD10-12 & 4 & $12.5 \pm 2.1$ & $4.2 \pm 4.9$ & $0.25 \pm 0.04$ & $0.15 \pm 0.01 * *$ & $1.65 \pm 0.28^{*}$ & NA & NA \\
\hline \multirow{3}{*}{ GD 17} & Control & 4 & $9.8 \pm 3.1$ & $0.0 \pm 0.0$ & $1.35 \pm 0.06$ & $0.44 \pm 0.04$ & $3.10 \pm 0.24$ & 0.0 & $0.0 \pm 0.0$ \\
\hline & GD7-9 & $4^{b}$ & $8.0 \pm 4.2$ & $28.6 \pm 37.0$ & $0.93 \pm 0.38^{*}$ & $0.32 \pm 0.06^{*}$ & $2.94 \pm 0.91$ & $96.8^{\# \#}$ & $36.1 \pm 47.5$ \\
\hline & GD10-12 & 4 & $9.8 \pm 2.2$ & $6.1 \pm 7.2$ & $1.00 \pm 0.24$ & $0.24 \pm 0.07^{* *}$ & $4.15 \pm 0.64^{*}$ & $74.4^{\# \#}$ & $0.0 \pm 0.0$ \\
\hline \multirow{3}{*}{ GD 21} & Control & 4 & $11.5 \pm 3.1$ & $0.0 \pm 0.0$ & $5.35 \pm 0.13$ & $0.51 \pm 0.03$ & $10.86 \pm 0.68$ & 2.2 & $0.0 \pm 0.0$ \\
\hline & GD7-9 & $4^{b}$ & $4.0 \pm 2.2^{*}$ & $63.6 \pm 20.0^{*}$ & $3.39 \pm 0.88^{*}$ & $0.28 \pm 0.07^{*}$ & $12.99 \pm 1.77$ & $85.7^{\# \#}$ & $53.0 \pm 32.7^{* *}$ \\
\hline & GD10-12 & $4^{b}$ & $8.5 \pm 4.0$ & $14.3 \pm 28.6$ & $4.22 \pm 1.39$ & $0.38 \pm 0.10$ & $11.89 \pm 3.43$ & $32.4^{\# \#}$ & $0.0 \pm 0.0$ \\
\hline
\end{tabular}

Mean \pm S.D.

a) Mean of individual litter values.

b) Except the dams with comleted resorption.

$*$, ** Significantly different from control group at $\mathrm{P}<0.05,<0.01$, respectively (Dunnett's test).

\#\# Significantly different from control at $\mathrm{P}<0.01$ ( $\mathrm{x}^{2}$ test).

NA, not available.

in the GD7-9 treated group. The embryonic/fetal weight showed a decrease from GD 13 onward in the GD7-9 treated group and a decrease or decreasing trend on GDs 13, 17 and 21 in the GD10-12 treated group. The placental weight showed a decrease from GD 13 onward in the GD7-9 treated group and a decrease or decreasing trend from GD 15 onward in the GD10-12 treated group. The IUGR rate on GDs 17 and 21 was increased in both DBTCl-treated groups. In the fetal external examination on GDs 17 and 21, acephalostomia, split mandible, cleft lip, gastroschisis, generalized edema, kinky tail, etc. were found in the GD7-9 treated group. No obvious macroscopic fetal external abnormalities were detected in the control and GD10-12 treated groups. The effect of DBT$\mathrm{Cl}$ on the embryo/fetus and placenta were detected in both DBTCl-treated groups, but the degree of effect was severer in the GD7-9 treated group than in the GD10-12 treated group. 


\section{Histopathological examination}

On GD 9.5

Conceptus with decidual mass: In the GD7-9 treated group, the apoptosis, characterized by pyknosis or karyorrhexis, phagocytosis and cell debris was detected by positive staining with the TUNEL assay in some embryos (Fig. 3), and the number of TUNEL positive cells was increased (Fig. 2). There was no histological change in the uterus, decidual mass, metrial gland, ectoplacental cone and yolk sac (Fig. 3). There was no difference of size, or the number of phospho-histone $\mathrm{H} 3$ positive cells in all parts between the control group and GD7-9 treated group (Fig. 2).

\section{During GDs 11-21}

Labyrinth zone: Apoptosis was detected in the trophoblastic septa and the number of TUNEL positive cells was increased on GDs 11 and 13 in the GD7-9 treated group and on GDs 13 and 15 in the GD10-12 treated group, resulting in the labyrinth zone hypoplasia (Figs. 4, 5). The number of phospho-histone $\mathrm{H} 3$ positive cells was decreased on GDs 11 and 13 in the GD7-9 treated group, and on GDs 13 and 15 in the GD10-12 treated group (Fig. 6). The labyrinth zone thickness diminished from GD 11 onward in the GD7-9 treated group, and from GD 13 onward in the GD10-12 treated group (Fig. 7).

Basal zone: The glycogen cell-islands were slightly decreased on GD 15, but there was no inhibition of the interstitial invasion of glycogen cell-like trophoblasts along the arterial canal from the basal zone to the metrial gland in both DBTCl-treated groups, compared with the control group. Some placentas on GDs 17 and 21 in the GD10-12 treated group showed multiple cysts, which consisted of cytolysis involving clusters of residual glycogen cell-islands (Fig. 4). The number of TUNEL positive cells was increased on GDs 11 and 21 in the GD7-9 treated group (Fig. 5). The number of phospho-histone $\mathrm{H} 3$ positive cells was decreased on GD 11 in the GD7-9 treated group and on GD 13 in the GD10-12 treated group (Fig. 6). The basal zone thickness diminished from GD 11 to GD 15 in the GD7-9 treated group, and from GD 13 to GD 15 in the GD10-12 treated group (Fig. 7).

Decidua basalis/Metrial gland: There was no histological change in all groups. There was no change in the number of TUNEL positive cells and phospho-histone $\mathrm{H} 3$ positive cells in the metrial gland in both DBTCl-treated groups, compared with the control group (Figs. 5, 6). There was no difference in the thickness of the metrial gland and decidua basalis in both DBTCl-treated groups, compared with the control group (Fig. 7).

Yolk sac: There was no histological change in the number of TUNEL positive cells in all groups (Fig. 5). The number of phospho-histone $\mathrm{H} 3$ positive cells was transiently decreased on GD 11 in the GD7-9 treated group (Fig. 6).

\section{Tissue concentration of tin by ICP-MS}

In the GD7-9 treated group, tin was detected in the conceptus with decidual mass on GD 9.5, and the placentas and yolk sac on GD 11 (Table 3). It was below the detection limit in the embryo on GD 11, but the detection sensitivity was low (detection limit, $80 \mathrm{ng} \mathrm{Sn} / \mathrm{g}$ ). In the GD10-12 treated group, tin was detected in the placenta, the embryo and yolk sac on GDs 13 and 14. In the control group, tin was below the detection limit in each tissue on GDs 9.5 and 14.

\section{Histological localization of tin in conceptus on GD 9.5 by LA-ICP-MS}

The LA-ICP-MS intensity of tin was increased in the conceptus (embryo, allantois, yolk sac, ectoplacental cone) and the decidual mass surrounding conceptus in the GD7-9 treated group (Fig. 3). There was no detection of tin in the conceptus in the control group.

\section{DISCUSSION}

It is reported that DBTCl induces various malformations characterized by craniofacial dysmorphism and its high susceptible period is on GD 7 or 8 (Ema et al., 1992). In the rat embryo culture, DBTCl induces the craniofacial defects in the embryo from GDs 8.5 and 9.5, but not from GD 11.5 (Ema et al., 1996). In the normal rat development, the craniofacial primordium is already formed in a 15-20 somite embryo on GD 9.5-10 (Butcher, 1929; Kaufman, 1990). The yolk sac during this period plays a role as a transient placenta, and is the only route for major transport between dams and embryo until the formation of allantoic and the establishment of chorioallantoic placenta on GD 11 1/2 (Jollie, 1990). Impaired structural and functional development of the yolk sac contributes to the embryo toxicity and teratogenicity in rats (Beckman et al., 1990), such as trypan blue (Rogers et al., 1985) and ethanol (Xu et al., 2005). Therefore, the embryonic toxicity and teratogenicity during early post-implantation are induced not only by the direct effect of toxicant on the embryo damage directly but also by the secondary effect from dysfunction of the yolk sac placenta. On the other hand, $\mathrm{DBTCl}$ is embryo-lethal in cynomolgus monkeys, but not teratogenic with the administration during the entire period of organogenesis (Ema et al., 2007, 2009). The yolk sac floats like a balloon within the exocoe- 
Effect of DBT on placental and fetal toxicity in rat
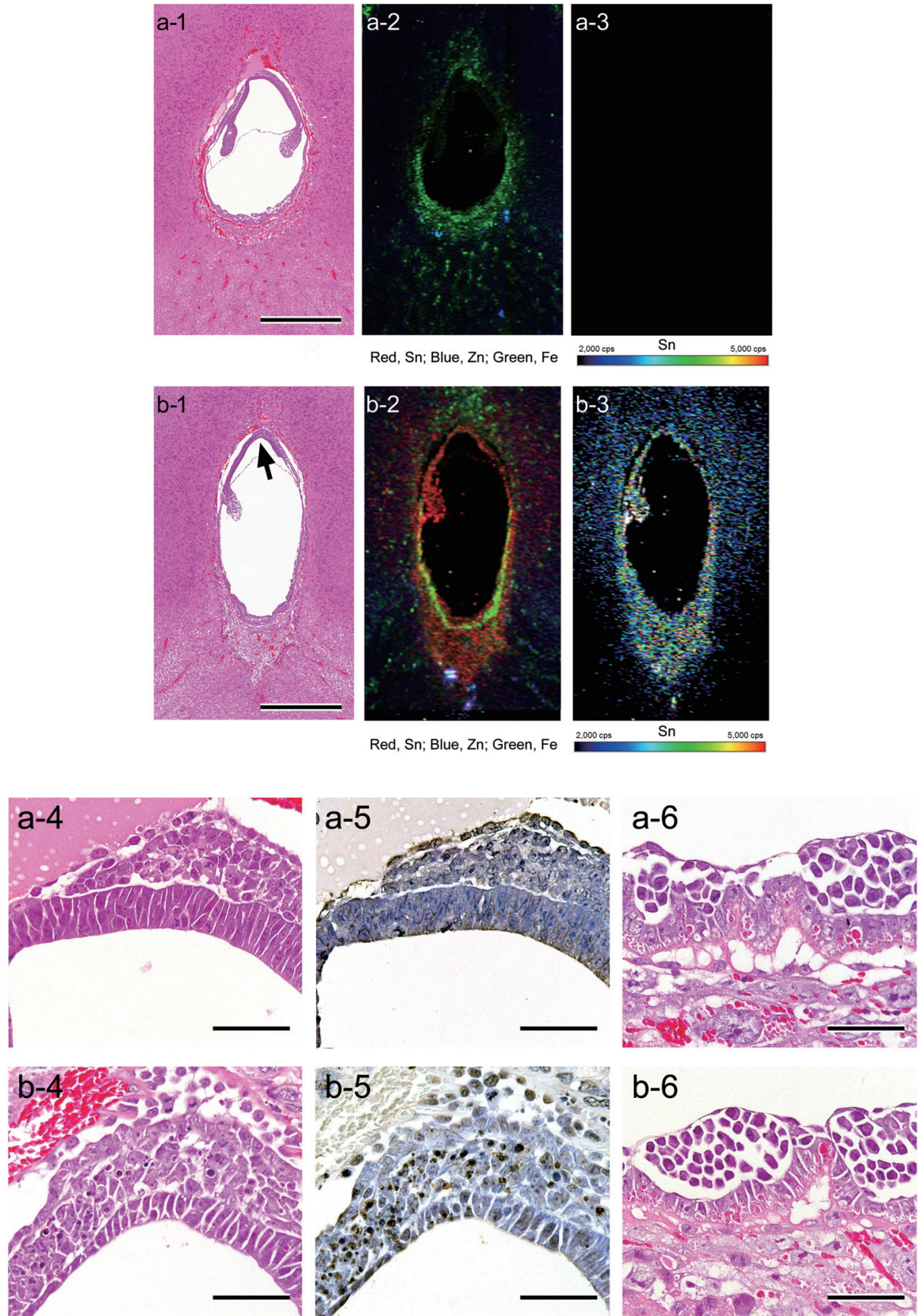

Fig. 3. Histopathological findings of conceptus on GD9.5. a. Overall conceptus in the control group. a-1, Low magnification. HE stain, Bar = $0.5 \mathrm{~mm}$; a-2, Imaging of Sn, Zn and Fe in a-1 by LA-ICP-MS (Sn, red; Zn, blue; Fe, green); a-3, Imaging of Sn in a-1 by LA-ICP-MS; a-4, High magnification of embryo of a-1. HE stain, Bar $=50 \mu \mathrm{m}$; a-5, TUNEL assay of the same site in a-4. Bar $=50 \mu \mathrm{m}$; a-6, High magnification of yolk sac. HE stain, Bar $=50 \mu \mathrm{m}$. b. Overall conceptus in the GD7-9 treated group. b-1, Low magnification. Apoptosis in the embryo (arrow). Showed the high magnification photograph to b-4. HE stain, Bar $=0.5 \mathrm{~mm}$; b-2, Imaging of $\mathrm{Sn}, \mathrm{Zn}$ and Fe in b-1 by LA-ICP-MS (Sn, red; Zn, blue; Fe, green); b-3, Imaging of Sn in b-1 by LA-ICP-MS. Increase in the LA-ICP-MS intensity of tin in the conceptus and decidual mass around it, compared with the control group.; b-4, High magnification of embryo of b-1. HE stain, Apoptosis, characterized by pyknosis or karyorrhexis, phagocytosis and cell debris in the embryo. Bar $=50 \mu \mathrm{m} ; \mathrm{b}-5$, TUNEL assay of the same site in b-4. Bar $=50 \mu \mathrm{m} ; \mathrm{b}-6$, High magnification of yolk sac. No change. HE stain, Bar $=50 \mu \mathrm{m}$. 


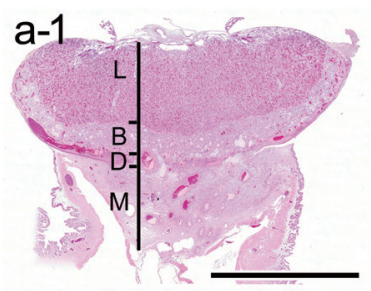

a-2
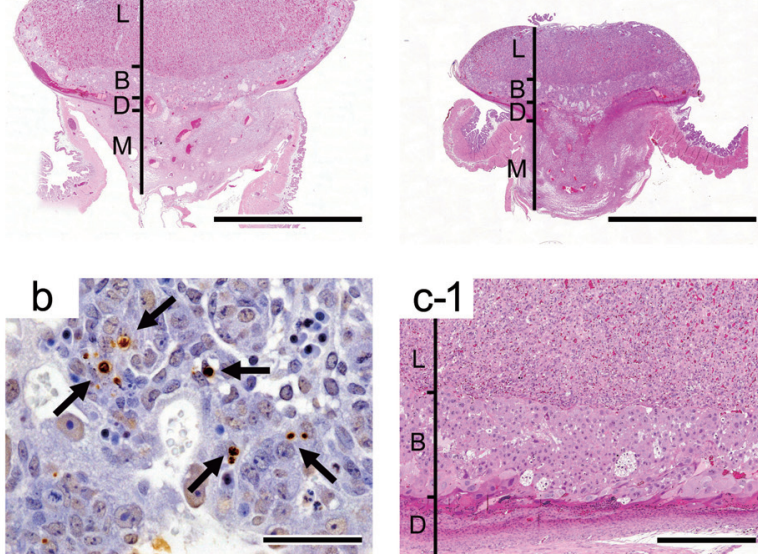

S. Furukawa et al.

a-3
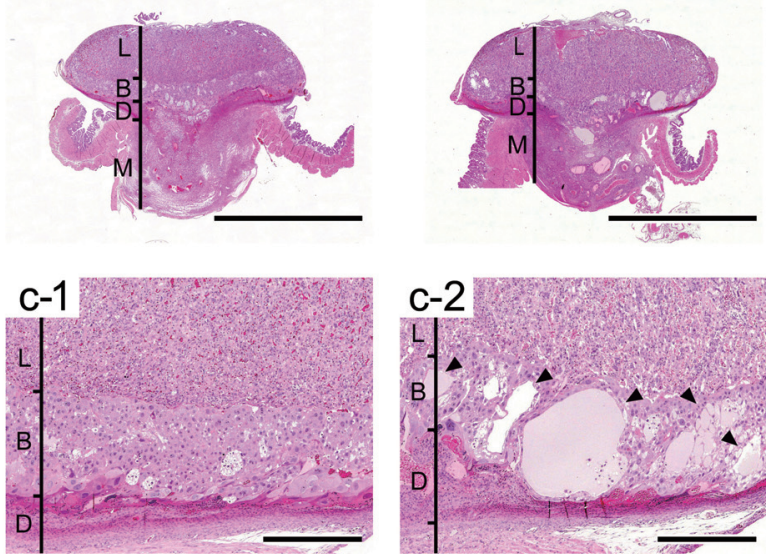

Fig. 4. Histopathological findings of placenta. a. Overall placental picture on GD 17. a-1, Control group; a-2, GD7-9 treated group; a-3, GD10-12 treated group. The labyrinth zone thickness diminished in both DBTCl-treated groups. Multiple cysts in the basal zone in the GD10-12 treated group. HE stain, Bar $=5,000 \mu \mathrm{m}$. b. Labyrinth zone on GD15 in the GD10-12 treated group. Apoptosis (arrow) in the trophoblastic septa. TUNEL assay, Bar $=60 \mu \mathrm{m}$. c. Basal zone on GD 17. c-1, Control group. Middle magnification of a-1; c-2, GD10-12 treated group. Middle magnification of a-3. Multiple cysts consisted of cytolysis involving clusters of residual glycogen cell-islands (arrow head). HE stain, Bar $=600 \mu \mathrm{m}$. L, labyrinth zone; B, basal zone; D, decidua basalis; $\mathrm{M}$, metrial gland.
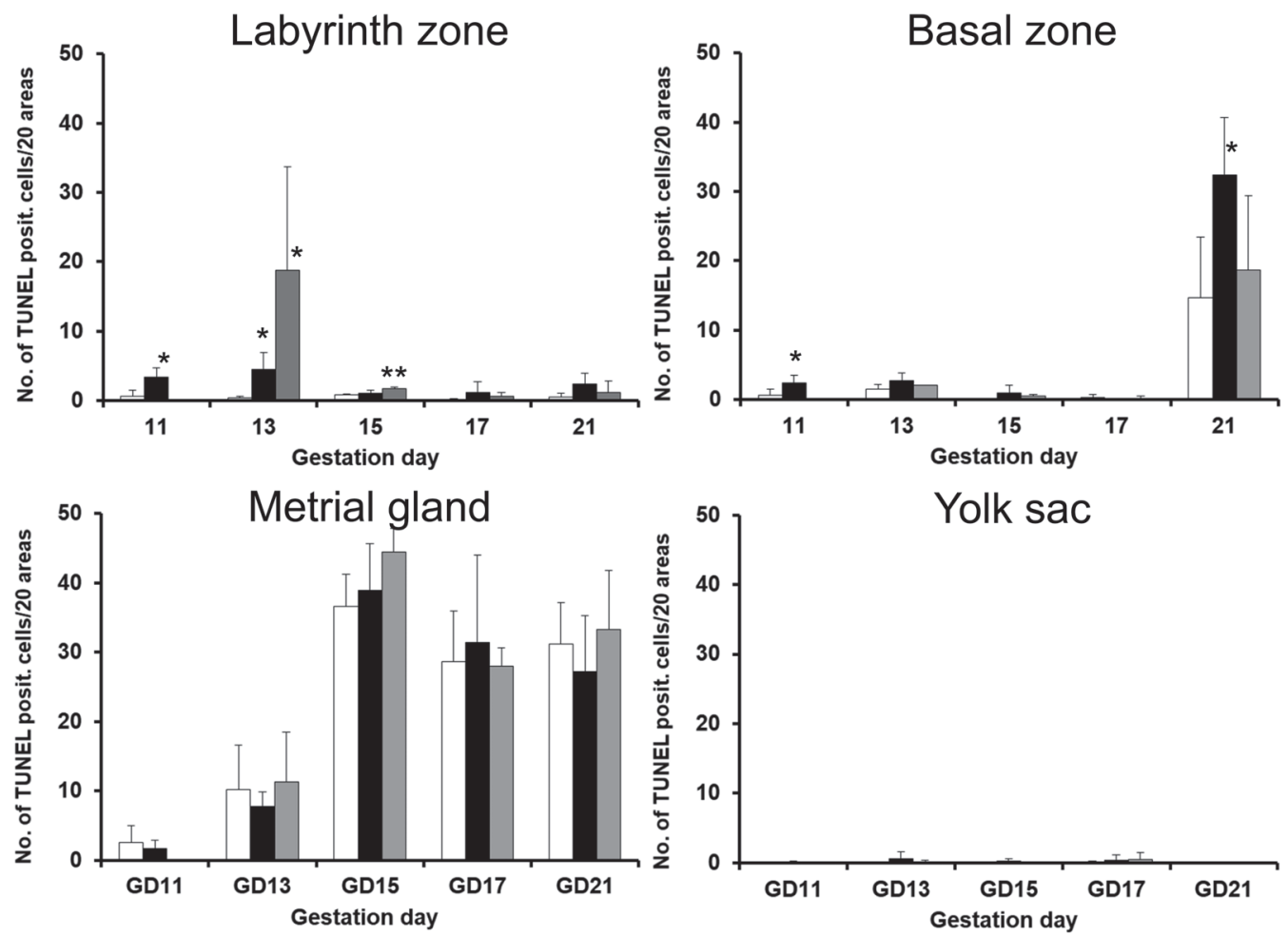

Fig. 5. Number of TUNEL positive cells in the labyrinth zone, basal zone metrial gland and yolk sac. $\square$, Control group; $\mathbf{\bullet}$, GD7-9 treated group; $\square$, GD10-12 treated group. Each value represents mean \pm S.D. Number of TUNEL positive cells in 20 areas by light microscopy with a 40x objective. * **Significantly different from control at $P<0.05,<0.01$, respectively (Student's t-test/ Dunnett's or Steel's test). 
Effect of DBT on placental and fetal toxicity in rat
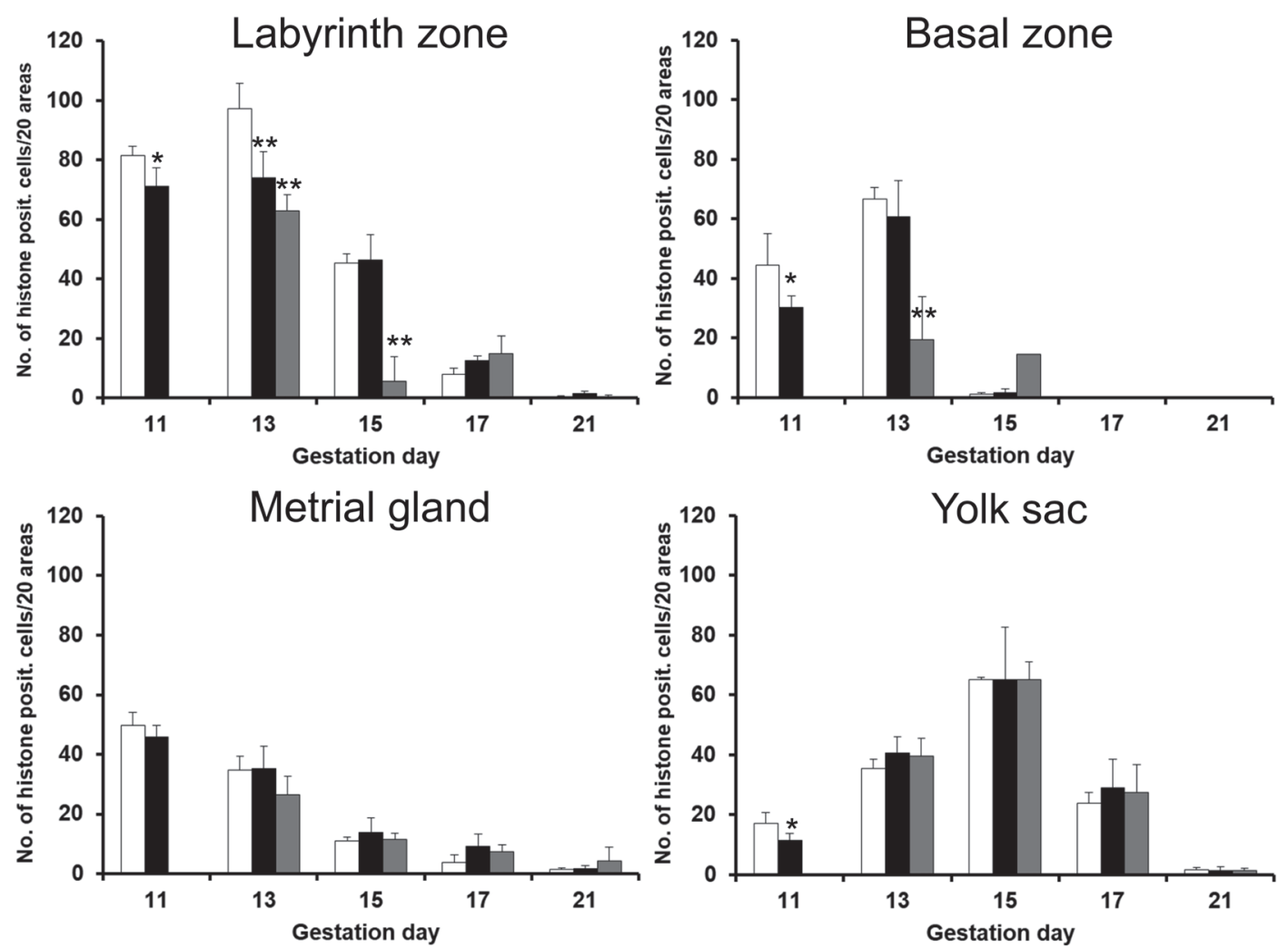

Fig. 6. Number of phospho-histone $\mathrm{H} 3$ positive cells in the labyrinth zone, basal zone metrial gland and yolk sac. $\square$, Control group; -, GD7-9 treated group; $\square$, GD10-12 treated group. Each value represents mean \pm S.D. Number of phospho-histone H3 cells in 20 areas by light microscopy with a $40 \mathrm{x}$ objective. $* * *$ Significantly different from control at $P<0.05,<0.01$, respectively (Student's t-test/Dunnett's test).

Table 3. Tissue concentration of tin by ICP-MS.

\begin{tabular}{|c|c|c|c|c|c|c|}
\hline Group & Autopsy & No. of dams & Embryo & Yolk sac & Placenta & Conceptus \\
\hline \multirow[b]{2}{*}{ Control } & GD 9.5 & 1 & NA & NA & NA & $<15$ \\
\hline & GD 14 & 1 & $<30$ & $<30$ & $<30^{\text {a) }}$ & NA \\
\hline \multirow{2}{*}{ GD7-9 } & GD 9.5 & 3 & NA & NA & NA & $290 \pm 27$ \\
\hline & GD 11 & 3 & $<80$ & $<10(2), 62(1)$ & $270 \pm 73^{a)}$ & NA \\
\hline \multirow{2}{*}{ GD10-12 } & GD 13 & 3 & $147 \pm 36$ & $977 \pm 816$ & $547 \pm 82^{b)}$ & NA \\
\hline & GD 14 & 3 & $63 \pm 9$ & $83 \pm 24$ & $267 \pm 62^{b)}$ & NA \\
\hline
\end{tabular}

\section{a) Fetal and maternal part of placenta}

b) Fetal part of placenta

Number in parentheses indicates number of animals.

NA, Not available.

lomic cavity and never becomes directly apposed to the chorion or the maternal uterine wall or uterine lumens in human and higher primates (Carney et al., 2004; Wooding and Burton, 2008). It is known that human yolk sac does not function as a placenta in the sense of being able to transfer nutrients between the maternal and embryonic circulations (Boyd, 2012; DeSesso et al., 2012). In addition, it is reported that the HBOC-201 (hemoglobinbased oxygen carriers)-induced embryo toxicity is indeed due to the damage of the yolk sac, and is not expected to impact human development (Stump et al., 2015). Therefore, the embryo toxicity induced by dysfunction of the yolk sac in rats cannot likely be extrapolated to humans. In the present study, apoptosis happens in the embryo 

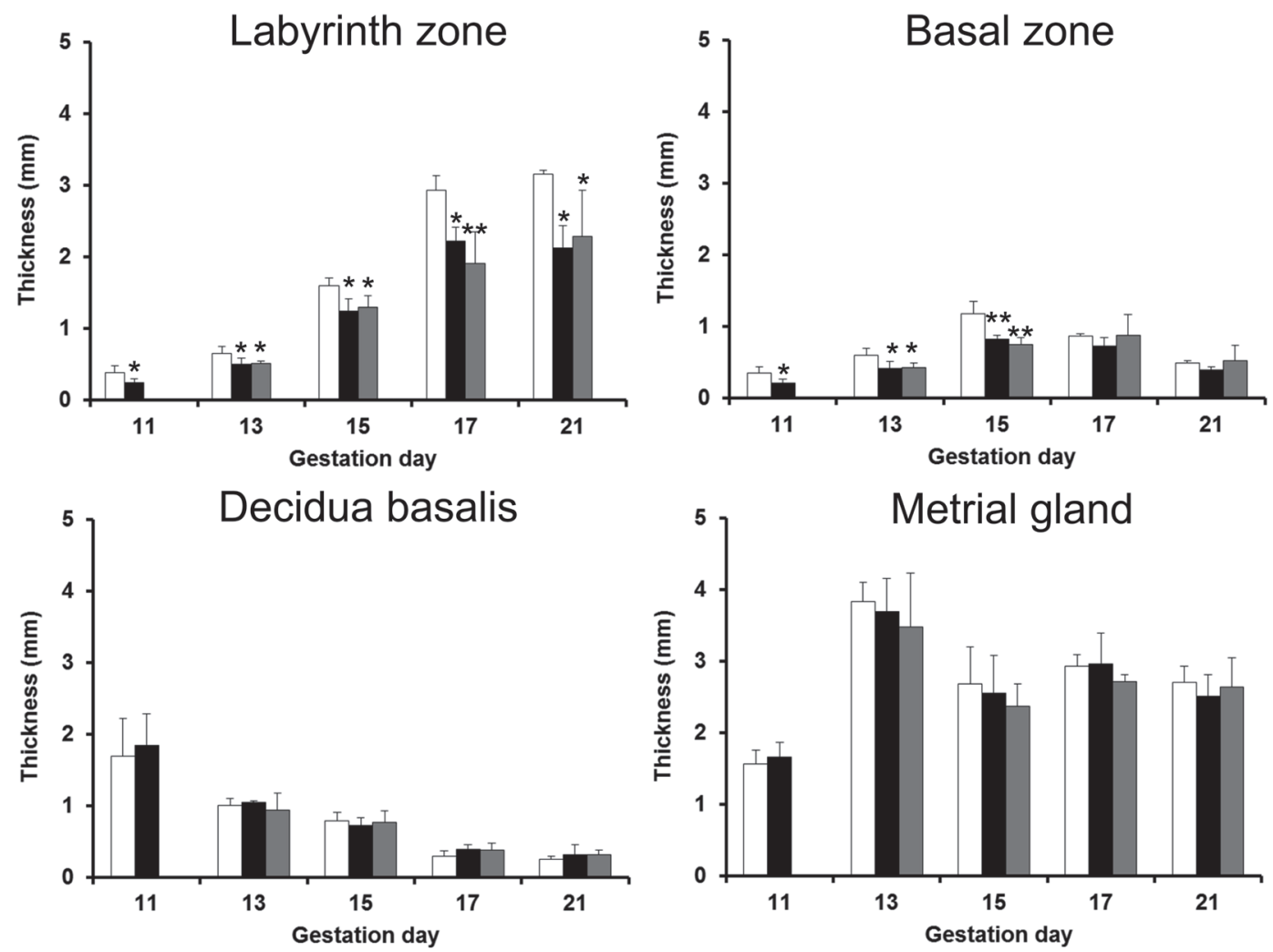

Fig. 7. The thickness of the labyrinth zone, basal zone, decidua basalis and metrial gland. $\square$, Control group; $\mathbf{m}$, GD7-9 treated group; $\square$, GD10-12 treated group. Each value represents mean \pm S.D. * ${ }^{* *}$ Significantly different from control at $P<0.05$, $<0.01$, respectively (Student's t-test/Dunnett's or Steel's test).

on GD 9.5, but there was no change in the yolk sac and ectoplacental cone of the conceptus, histologically. It is known that DBTCl induces cytotoxicity (apoptosis and/ or necrosis) and has anti-proliferative activity in some in vitro studies (Boyer, 1989; Hoth et al., 2005; Ferreira et $a l ., 2013)$. It is also reported that the cytotoxicity is attributed to the inhibition of $\alpha$-ketoacid oxidation, resulting from a decrease in intercellular ATP levels and the inhibition of mitochondrial respiration (Dudimah et al., 2007; Ueno et al., 2003). On the other hand, the LA-ICP-MS analysis is a very useful method for the investigation of elemental distributions in paraffin sections and is becoming one of the important tools for pathology (Yamagishi et al., 2016; Egger et al., 2015). In the present study, it was confirmed that tin was histologically detected in the embryo, yolk sac and ectoplacental cone in the LA-ICPMS analysis. From these results, it is concluded that the embryo toxicity might result from the direct effect of DBTCl, but not from dysfunction in the yolk sac placental activity. Thus, it is considered that the yolk sac pla- centa actively absorbs DBTCl by endocytosis of materials, presumably maternal serum proteins, and transports them to the embryo through the yolk sac circulation. The embryonic apoptosis is induced, leading to malformations and fetal resorption. In addition, it is considered that the embryo in this period is specifically sensitive to DBT$\mathrm{Cl}$-induced apoptosis, compared with the yolk sac, ectoplacental cone and decidua. It is speculated that the species difference of $\mathrm{DBTCl}$ in the malformations between rats and cynomolgus monkeys might be due to the uptake ability of DBTCl via the yolk sac placenta in rats or the differential sensitivity of the embryonic cells to DBTCl, but we could not prove this from the results in the current study. Furthermore, it is known that butyltin compounds show some reproductive/developmental toxicities in rats, and are different in the susceptibility and spectrum of developmental toxicity (Ema et al., 1995). DBT induces the most severe malformations in the rat developmental toxicity among them (Ema, 2007). However, DBT induces neither RXR nor PPAR $\gamma$ transactivation, unlike 
Effect of DBT on placental and fetal toxicity in rat

other butyltin compounds (Hiromori et al., 2016), and the cytotoxic effects in vitro of tributyltin (TBT) is the most toxic among them (Hoth et al., 2005). In order to clarify the different adverse outcome pathways of developmental toxicity induced by butyltin compounds, it is necessary to compare the further detailed histopathological findings of the embryos/fetuses and placenta from the DBT and TBTexposed rats.

In the chorioallantoic placenta, the labyrinth zone has higher cell proliferative activity for a longer period than that of other parts of placenta. The labyrinth zone becomes a major part of placenta with advancing pregnancy, and the placental weight change reflects its development in the middle and late gestation (Furukawa et al., 2013a). The labyrinth zone is the susceptible target tissue of placenta for toxicants that are apoptotic agents and cell proliferation inhibitors, particularly, anti-cancer drugs. The cell proliferative activity in the labyrinth zone is at its peak on GD 13 and then reduces toward late gestation (Furukawa et al., 2015). Therefore, the effect of these agents on the labyrinth zone is closely related to the proliferation period, and the developed lesions depend on the timing of treatment period, such as 6-mercaptopurine (Furukawa et al., 2011a) and cisplatin (Furukawa et al., 2013b). By contrast, chlorpromazine induces the nonspecific transient developmental retardation of placenta caused by apoptosis independently of the cell proliferation period (Furukawa et al., 2015). In the present study, DBTCl induced apoptosis and/or mitotic inhibition in the fetal part of placenta, particularly the labyrinth zone, but not in the maternal part of placenta in both DBTCl-treated groups. It showed no remarkable difference in comparison with the lesions and thickness of the labyrinth zone between both DBTCl-treated groups. Thus, it is suggested that DBTCl-induced placental hypoplasia results mainly from a non-specific transient developmental retardation of the labyrinth zone, caused by apoptosis and mitotic inhibition. It appears that there are no obvious specific sensitive periods of the DBTCl-induced lesions in the labyrinth zone. In addition, it was considered that the poor reproductive performance including IUGR was not only caused by the direct effect of DBTCl on embryo, but also by a secondary effect from the damage of labyrinth zone. On the other hand, the embryos on GD 9.5 showed no mitotic inhibition despite inducing apoptosis more than the placentas. It was considered that the toxic effects of DBTCl are different between the chorioallantoic placenta and embryo, although we could not clarify the cause in the current study.

In the basal zone, the cystic degeneration of glycogen cells is the condition describing abnormal reten- tion of extensive cytoplasmic vacuolation within glycogen cells (Furukawa et al., 2011b). The glycogen cells are the site of the glycogen storage that is produced from maternal glucose (Nishimura et al., 2013). The glycogen in these cells is an energy substrate for fetus and the disappearance of the glycogen cell islands corresponds to the increased demand for energy for the final period of fetal growth (Vercruysse et al., 2006; Sferruzzi-Perri et al., 2009). In the normal rat placenta development, the glycogen cells transiently appear on GD 12 and form small clusters on GD 14. They develop into glycogen cell islands and compose a large part of the basal zone on GDs 15 and 16. After that, the number of glycogen cells is decreased and the basal zone is thinned until GD 18. In the present study, the cystic degeneration of glycogen cells was observed in the GD10-12 treated group but not the GD7-9 treated group. However, the DBTCl-induced fetal toxicity was higher in the GD7-9 treated group than in the GD10-12 treated group. Therefore, it is suggested that the cystic degeneration is resulting from transient developmental retardation of the basal zone in the developmental process, caused by mitotic inhibition during the proliferation period. In addition, it is considered that the cystic degeneration does not necessarily imply the suppression of energy supply to the fetus or relate to the fetal toxicity.

In the maternal part of placenta, the decidua acts as isolation of the implanting blastocysts from the maternal tissue, nutrient provision and hormone production (Wooding and Burton, 2008). DBTCl induces preimplantation embryonic loss in rats, resulting from suppression of the decidual cell response (Harazono and Ema, 2003). Since progesterone and prolactin are considered essential for the decidual development (Yochim and De Feo, 1962), the primary mechanism for the implantation failure is the decline in progesterone levels caused by DBTCl-treatment during GDs 0 - 3 (Ema et al., 2003). On the other hand, after implantation, the decidua and metrial gland are detected from GD 6 and forms at least GD 9.5 (de Rijk et al., 2002). In the present study, there was no effect on the thickness of the metrial gland and decidua basalis without the histopathological change despite the DBTCl-treatment during their formation period. Therefore, we suggest that the decidual cells and metrial gland cells are less sensitive to DBTCl-induced cytotoxicity than the trophoblasts in the labyrinth zone, although it is unclear what causes the differential sensitivity among these cells in the present study.

In conclusion, it is speculated that the embryo is specifically sensitive to DBTCl-induced apoptosis, and the malformations and fetal resorption resulted from apopto- 


\section{S. Furukawa et al.}

sis in the embryo caused by the direct effect of DBTCl absorbed by the yolk sac placenta. The DBTCl-induced lesions in the chorioallantoic placenta were a non-specific transient developmental retardation in the fetal parts of placenta, resulting from apoptosis and mitotic inhibition, leading to induce induction of IUGR.

\section{ACKNOWLEDGMENTS}

The authors would like to thank Dr. Makoto Ema (National Institute of Advanced Industrial Science and Technology) for suggesting the topic treated in this paper, Ms. Ayako Igarashi (Nissan Chemical Industries, Ltd.) for the excellent technical advice, Ms. Kaori Maejima, Ms. Hiromi Asako, Mr. Atsushi Funakoshi, and Mr. Yoshinori Tanaka (Nissan Chemical Industries, Ltd.) for their excellent technical assistance, and Mr. Yasuo Kuroki (Thermo Fisher Scientific Inc.) for the LA-ICP-MS analysis.

Conflict of interest---- The authors declare that there is no conflict of interest.

\section{REFERENCES}

Beckman, D.A., Koszalka, T.R., Jensen, M. and Brent, R.L. (1990): Experimental manipulation of the rodent visceral yolk sac. Teratology, 41, 395-404.

Boyd, K.L. (2012): Female Reproductive System. In Comparative Anatomy and Histology; A Mouse and Human Atlas (Treuting, P.M. and Dintzis, S.M., eds.), pp.253-284, Academic Pres, Amsterdam.

Boyer, I.J. (1989): Toxicity of dibutyltin, tributyltin and other organotin compounds to humans and to experimental animals. Toxicology, 55, 253-298.

Butcher, E.O. (1929): The development of the somites in the white rat (mus norvegicus albinus) and the fate of the myotomes, neural tube, and gut in the tail. Dev. Dyn., 44, 381-439.

Carney, E.W., Scialli, A.R., Watson, R.E. and DeSesso, J.M. (2004): Mechanisms regulating toxicant disposition to the embryo during early pregnancy: An interspecies comparison. Birth. Defects Res. Part C, 72, 345-360.

Correia-da-Silva, G., Bell, S.C., Pringle, J.H. and Teixeira, N.A. (2004): Patterns of uterine cellular proliferation and apoptosis in the implantation site of the rat during pregnancy. Placenta, 25, 538-547.

de Rijk, E.P., van Esch, E. and Flik, G. (2002): Pregnancy dating in the rat: placental morphology and maternal blood parameters. Toxicol. Pathol., 30, 271-282.

DeSesso, J.M., Williams, A.L., Ahuja, A., Bowman, C.J. and Hurtt, M.E. (2012): The placenta, transfer of immunoglobulins, and safety assessment of biopharmaceuticals in pregnancy. Crit. Rev. Toxicol., 42, 185-210.

Dudimah, F.D., Gibson, C. and Whalen, M.M. (2007): Effect of dibutyltin on ATP levels in human natural killer cells. Environ. Toxicol., 22, 117-123.

Egger, A.E., Kornauth, C., Haslik, W., Hann, S., Theiner, S., Bayer, G., Hartinger, C.G., Keppler, B.K., Pluschnig, U. and
Mader, R.M. (2015): Extravasation of Pt-based chemotherapeutics - bioimaging of their distribution in resectates using laser ablation-inductively coupled plasma-mass spectrometry (LAICP-MS). Metallomics, 7, 508-515.

Ema, M. (2007): Reproductive and developmental toxicity of organotin compounds. Bull. Natl. Inst. Health Sci., 125, 35-50.

Ema, M., Arima, A., Fukunishi, K., Matsumoto, M., Hirata-Koizumi, M., Hirose, A. and Ihara, T. (2009): Developmental toxicity of dibutyltin dichloride given on three consecutive days during organogenesis in cynomolgus monkeys. Drug Chem. Toxicol., 32, 150-157.

Ema, M., Fukunishi, K., Matsumoto, M., Hirose, A., Kamata, E. and Ihara, T. (2007): Developmental toxicity of dibutyltin dichloride in cynomolgus monkeys. Reprod. Toxicol., 23, 12-19.

Ema, M., Harazono, A., Hirose, A. and Kamata, E. (2003): Protective effects of progesterone on implantation failure induced by dibutyltin dichloride in rats. Toxicol. Lett., 143, 233-238.

Ema, M., Itami, T. and Kawasaki, H. (1991): Teratogenicity of di-nbutyltin dichloride in rats. Toxicol. Lett., 58, 347-356.

Ema, M., Itami, T. and Kawasaki, H. (1992): Susceptible period for the teratogenicity of di-n-butyltin dichloride in rats. Toxicology, 73, 81-92.

Ema, M., Iwase, T., Iwase, Y., Ohyama, N. and Ogawa, Y. (1996): Change of embryotoxic susceptibility to di-n-butyltin dichloride in cultured rat embryos. Arch. Toxicol., 70, 742-748.

Ema, M., Kurosaka, R., Amano, H. and Ogawa, Y. (1995): Comparative developmental toxicity of butyltin trichloride, dibutyltin dichloride and tributyltin chloride in rats. J. Appl. Toxicol., 15, 297-302.

Engelbregt, M.J., van Weissenbruch, M.M., Popp-Snijders, C., Lips, P. and Delemarre-van de Waal, H.A. (2001): Body mass index, body composition, and leptin at onset of puberty in male and female rats after intrauterine growth retardation and after early postnatal food restriction. Pediatr. Res., 50, 474-478.

Ferreira, M., Blanco, L., Garrido, A., Vieites, J.M. and Cabado, A.G. (2013): In vitro approaches to evaluate toxicity induced by organotin compounds tributyltin (TBT), dibutyltin (DBT), and monobutyltin (MBT) in neuroblastoma cells. J. Agric. Food Chem., 61, 4195-4203.

Furukawa, S., Hayashi, S., Abe, M., Hagio, S., Irie, K., Kuroda, Y., Ogawa, I. and Sugiyama, A. (2013a): Background data on developmental parameters during the gestation period in rats. J. Toxicol. Pathol., 26, 83-88.

Furukawa, S., Hayashi, S., Usuda, K., Abe, M., Hagio, S. and Ogawa, I. (2013b): Effect of cisplatin on rat placenta development. Exp. Toxicol. Pathol., 65, 211-217.

Furukawa, S., Hayashi, S., Usuda, K., Abe, M. and Ogawa, I. (2011a): The relationship between fetal growth restriction and small placenta in 6-mercaptopurine exposed rat. Exp. Toxicol. Pathol., 63, 89-95.

Furukawa, S., Hayashi, S., Usuda, K., Abe, M., Hagio, S. and Ogawa, I. (2011b): Toxicological pathology in the rat placenta. J. Toxoicol. Pathol., 24, 95-111.

Furukawa, S., Nagaike, M. and Ozaki, K. (2017): Databases for technical aspects of immunohistochemistry. J. Toxoicol. Pathol., 30, 79-107.

Furukawa, S., Tsuji, N., Hayashi, S., Abe, M., Hagio, S., Yamagishi, Y., Kuroda, Y. and Sugiyama, A. (2015): Histomorphological comparison of rat placentas by different timing of chlorpromazine-administration. Exp. Toxicol. Pathol., 67, 443-452.

Harazono, A. and Ema, M. (2003): Suppression of decidual cell response induced by dibutyltin dichloride in pseudopregnant 
Effect of DBT on placental and fetal toxicity in rat

rats: as a cause of early embryonic loss. Reprod. Toxicol., 17, 393-399.

Hiromori, Y., Yui, H., Nishikawa, J., Nagase, H. and Nakanishi, T. (2016): Organotin compounds cause structure-dependent induction of progesterone in human choriocarcinoma Jar cells. J. Steroid. Biochem. Mol. Biol., 155, 190-198.

Hoth, A., Johannisson, R., Syed Ali, S., Schulze, J. and Siegers, C. (2005): Cytotoxicity of organotin compounds in different cultured cell lines. Toxicol. Indust. Health, 21, 131-136.

Huang, J., Zhou, S., Pig, J., Pan, X., Liang, G., Xu, D., Kou, H., Bao, C. and Wang, H. (2012): Role of p53-dependent placental apoptosis in the reproductive and developmental toxicities of caffeine in rodents. Clin. Exp. Pharmacol. Physiol., 39, 357-363.

Jollie, W.P. (1990): Development, morphology, and function of the yolk-sac placenta of laboratory rodents. Teratology, 41, 361-381.

Kaufman, M.H. (1990): Morphological stages of postimplantation embryonic development. In Postimplantation mammalian embryos. A practical approach. (Copp, A.J. and Cockroft, D.L. eds.) pp.81-91. Oxford IRL Press, Oxford.

Nishimura, K., Nakano, N., Chowdhury, V.S., Kaneto, M., Torii, M., Hattori M.A., Yamauchi, N. and Kawai, M. (2013): Effect of PPAR $\beta / \delta$ agonist on the placentation and embryo-fetal development in rats. Birth Defects Res. B. Dev. Reprod. Toxicol., 98, 164-169.

Rogers, J.M., Daston, G.P., Ebron, M.T., Carver, B., Stefanadis, J.G. and Grabowski, C.T. (1985): Studies on the mechanism of trypan blue teratogenicity in the rat developing in vivo and in vitro. Teratology, 31, 389-399.

Sferruzzi-Perri, A.N., Macpherson, A.M., Roberts, C.T. and Robertson, S.A. (2009): Csf2 null mutation alters placental gene expression and trophoblast glycogen cell and giant cell abundance in mice. Biol. Reprod., 81, 207-221.

Smith, S.C., Baker, P.N. and Symonds, E.M. (1997): Placental apoptosis in normal human pregnancy. Am. J. Obstet. Gynecol., 177,
57-65.

Stump, D.G., Holson, J.F., Harris, C., Pearce, L.B., Watson, R.E. and DeSesso, J.M. (2015): Developmental toxicity in rats of a hemoglobin-based oxygen carrier results from impeded function of the inverted visceral yolk sac. Reprod. Toxicol., 52, 108-117.

Ueno, S., Kashimoto, T., Susa, N., Shiota, Y., Okuda, M., Mutoh, K., Hoshi, F., Watanabe, K., Tsuda, S., Kawazoe, S., Suzuki, T. and Sugiyama, M. (2003): Effects of butyltin compounds on mitochondrial respiration and its relation to hepatotoxicity in mice and guinea pigs. Toxicol. Sci., 75, 201-207.

Vercruysse, L., Caluwaerts, S., Luyten, C. and Pijnenborg, R. (2006): Interstitial trophoblast invasion in the decidua and mesometrial triangle during the last third of pregnancy in the rat. Placenta, 27, 22-33.

Waddell, B.J., Hisheh, S., Dharmarajan, A.M. and Burton, P.J. (2000): Apoptosis in rat placenta is zone-dependent and stimulated by glucocorticoids. Biol. Reprod., 63, 1913-1917.

Wooding, P. and Burton, G. (2008): Implantation, maternofetal exchange and vascular relationships. In Comparative Placentation. Structures, Functions and Evolution (Wooding, P. and Burton, G., eds.) pp.47-81, Springer-Verlag, Berlin.

Xu, Y., Xiao, R. and Li, Y. (2005): Effect of ethanol on the development of visceral yolk sac. Hum. Reprod., 20, 2509-2516.

Yamagishi, Y., Furukawa, S., Tanaka, A., Kobayashi, Y. and Sugiyama, A. (2016): Histopathological localization of cadmium in rat placenta by LA-ICP-MS analysis. J. Toxicol. Pathol., 29, 279-283.

Yamada, S., Fujii, Y., Mikami, E., Kawamura, N., Hayakawa, J., Aoki, K., Fukaya, M. and Terao, C. (1993): Small-scale survey of organotin compounds in household commodities. J. AOAC. Int., 76, 436-411.

Yochim, J.M. and De Feo, V.J. (1962): Control of decidual growth in the rat by steroid hormones of the ovary. Endocrinology, 71, 134-142. 